\title{
Enhancing Nursing Students' Understanding of Oral Health: An Educational Intervention with an Interprofessional Component
}

Shelley Spurr Dr.

University of Saskatchewan, College of Nursing, shelley.spurr@usask.ca

Jill Bally Dr.

University of Saskatchewan, College of Nursing, jill.bally@usask.ca

Alyssa Hayes Dr.

University of Saskatchewan, College of Dentistry, alyssa.hayes@usask.ca

Marcella Ogenchuk Dr.

Univeristy of Saskatchewan, College of Nursing.., marcella.ogenchuk@usask.ca

Krista Trinder

University of Saskatchewan College of Medicine, krista.trinder@usask.ca

Follow this and additional works at: https://qane-afı.casn.ca/journal

Part of the Family Practice Nursing Commons, Maternal, Child Health and Neonatal Nursing Commons, Pediatric Dentistry and Pedodontics Commons, Pediatric Nursing Commons, and the Public Health and Community Nursing Commons

\section{Recommended Citation}

Spurr, Shelley Dr.; Bally, Jill Dr.; Hayes, Alyssa Dr.; Ogenchuk, Marcella Dr.; and Trinder, Krista (2017) "Enhancing Nursing Students' Understanding of Oral Health: An Educational Intervention with an Interprofessional Component," Quality Advancement in Nursing Education - Avancées en formation infirmière: Vol. 3: Iss. 1, Article 5.

DOI: https://doi.org/10.17483/2368-6669.1091

This Article is brought to you for free and open access by Quality Advancement in Nursing Education - Avancées en formation infirmière. It has been accepted for inclusion in Quality Advancement in Nursing Education - Avancées en formation infirmière by an authorized editor of Quality Advancement in Nursing Education - Avancées en formation infirmière. 


\section{Enhancing Nursing Students' Understanding of Oral Health: An Educational Intervention with an Interprofessional Component}

\section{Cover Page Footnote}

The authors acknowledge Saskatoon Health Region for permission to revise the survey questionnaire. Thank you to Leslie Topola SDT (Health Region Manager) and Cynthia Ostafie SDT (Dental Health Educator) for editing the survey. Les auteurs remercient la Région sanitaire de Saskatoon (Saskatoon Health Region) de leur avoir permis de modifier le questionnaire du sondage. Remerciements aux thérapeutes dentaires Leslie Topola, SDT (gestionnaire de la Région sanitaire) et à Cynthia Ostafie, SDT (éducatrice en santé dentaire) pour leur révision du sondage. 


\section{Introduction}

Oral disease is a highly preventable condition, yet it remains one the most common childhood chronic diseases worldwide (Federal Provincial and Territorial Dental Working Group, 2012; Petersen, 2009). Although the oral health status of Canadians has improved dramatically in recent decades, many children still lack access to regular dental care, and this has resulted in poor oral health in this population (Canadian Dental Association, 2010). Similarly, in the United States, an estimated $25 \%$ of children $2-5$ years of age and 50\% of adolescents 12-15 years of age suffer from tooth decay (National Children's Oral Health Foundation, 2012). On a global level, the availability of oral health services in many countries remains limited with little attention given to preventive or restorative care (Callister, 2008; Federal Provincial and Territorial Dental Working Group, 2012; National Children's Oral Health Foundation, 2012). Although the World Health Organization (WHO) has worked to increase awareness worldwide, oral disease remains a serious public health problem in high-income countries and a significant burden for developing countries (Petersen, 2009).

Health care professionals play a key role in the promotion of oral health care in pediatric practice, and they can improve the availability of oral health services and reduce dental caries (Minah et al., 2008; Wawrzyniak, Boulter, Giotopoulos, \& Zivitski, 2006). However, pediatric care providers lack competence in performing oral health assessments and prevention services, and there is a need for additional oral health pedagogy in pediatric health professional education programs (Caspary, Krol, Boulter, Keels, \& Romano-Clarke, 2008; Golinveaux et al., 2013).

Despite the findings of research conducted in this area, few studies have examined the degree to which oral health education is included in nursing curricula. One American study found that providing education to nurse practitioner students improved knowledge, confidence, and behaviours regarding the incorporation of oral health care into well-child visits (Golinveaux et al., 2013). However, to our knowledge, no published studies report the pediatric oral health knowledge and competence of undergraduate nursing education students. Providing oral health education to undergraduate nursing students could improve their competence and ability to provide oral health care services to children and adolescents, including assessment, education, and referrals.

Thus, the purpose of the pilot study was to examine if an oral health education intervention, which included a two-hour lecture and a one-hour clinical lab experience, delivered to third-year undergraduate nursing students would improve their knowledge of pediatric oral health care. Herein, we define oral health as a state of the oral and related tissues and structures, including oral infections and trauma, dental decay and erosion, gingivitis, and periodontal disease, as per the Canadian Dental Association (2012).

\section{Background/literature}

Oral health is an important determinant for quality of life, as the craniofacial complex allows a person to speak, smell, taste, and chew and also provides protection against infections and environmental threats (Canadian Dental Association, 2012; National Children's Oral Health Foundation, 2012). The WHO clearly outlines how oral health is integral and essential to general health (Petersen, 2009). Despite this global recognition and focus, oral health is often overlooked or neglected by non-dental professionals (Blevins, 2011). 
There is a myriad of evidence on the risk factors and serious health effects of pediatric dental disease (Federal Provincial and Territorial Dental Working Group, 2012). The consequences of poor oral health are significant. Dental caries cause pain, making it difficult to chew and digest food, to learn, and to socialize with others (Canadian Dental Association, 2012; Petersen, 2009). Periodontal disease can lead to tooth loss and is associated with an increased risk of future cardiovascular disease, diabetes, and cancer (Canadian Dental Association, 2012c; Federal Provincial and Territorial Dental Working Group, 2012; Petersen, 2009). Research highlights the relationship between poor oral hygiene and ventilator-associated pneumonia, bacterial colonization of the oropharynx, and higher nosocomial infections (Johnstone, Spence, $\&$ Koziol-McLain, 2010). Thus, the importance of adequate oral health care cannot be overemphasized (Kullberg et al., 2010).

Similar to other aspects of health, the oral health of children and adolescents is influenced by broad determinants of health, such as income, access to health services, and education (Federal Provincial and Territorial Dental Working Group, 2012; Petersen, 2009). As such, it must be realized that a single professional, such as a community dentist, would have limited impact on the broad determinants of health, and, thus, an integrated approach is necessary (Federal Provincial and Territorial Dental Working Group, 2012; Hallas \& Shelley, 2009; Hayes, 2014; Satcher, 2009). Hayes (2014) argues that a sustainable reduction in outcomes associated with oral health requires all health care professionals to recognize and attend to oral health needs. Similarly, pediatric nursing education should include oral health, and, as Hayes (2014) recommends for practice, such education should be predicated on an interprofessional approach.

Over the years, the amount and depth of research into interprofessional education (IPE) has increased significantly. However, there is a lack of clarity related to the definition of this concept. The Center for Advancement in Interprofessional Education defines IPE as occurring when "two or more professions learn with, from and about each other to improve collaboration and the quality of care" (Centre For the Advancement of Interprofessional Education, 2002, p. 1). Similarly, the Interprofessional Education Consortium outlined IPE as a "learning process that prepares professionals through interdisciplinary education and diverse experiences to work collaboratively to meet the needs of children, youth, and families." (Interprofessional Education Consortium, 2002, p. 2). This educational approach provides more coordinated and comprehensive care, places priority on the preferences of the client, and can foster respect for the knowledge and skills of all health care professionals (Kearney, 2008). IPE for collaborative practice is an important innovation nationally and globally (Lapkin, Levett-Jones, \& Gilligan, 2011). Similar to the operational definition outlined by the Canadian Interprofessional Health Collaborative, in this article IPE was defined more broadly as health care professionals learning collaboratively within and across their discipline in order to gain the knowledge, skills, and values required to work with other health care professionals (Canadian Interprofessional Health Collaborative, 2007, p. 8). Findings from this unique intervention study-which included an IPE component - will add valuable knowledge to our understandings of oral health care, and could provide nursing students with the knowledge and tools required to continue implementing oral health in their future clinical practice.

Although oral health care is generally included in nursing education curricula, informal comments from nursing students elicited concerns about the depth of knowledge and skills being taught in the local program. One example included an unsolicited discussion within a group of seven nursing students who expressed the opinion that oral hygiene was the only aspect learned 
and implemented in practice. Another comment made by these same nursing students was that oral health care was frowned upon by nurses in practice and the prioritization of other important nursing skills was suggested. These views are supported in international literature, which indicates that nurses and educators tend to overlook this important component of nursing care (Blevins, 2011; Jablonski, Mertz, Featherstone, \& Fulmer, 2014; Johnstone et al., 2010). Research in pediatric intensive care units in New Zealand found that oral hygiene varied widely and was often inadequate (Johnstone et al., 2010). Researchers from Sweden found a discrepancy between oral care knowledge and actual oral care behaviour among nurses (Kullberg et al., 2010). Hallas and Shelley (2009) conclude that although oral health was included in pediatric nurse practitioner programs in the United States, gaps in knowledge exist and little evidence documents the extent to which oral health educational goals are being achieved. Similarly, there is limited research into oral health knowledge and practice in baccalaureate nursing education programs globally. However, it is clear that it is essential to educate nursing students as they will become the future workforce in pediatric nursing practice and can contribute to addressing and resolving this public health concern. Thus, the comments from nursing students and findings from international research studies support the need for more in depth, comprehensive research into student knowledge of oral health care in baccalaureate nursing education.

\section{Methods}

This research was approved by the behavioural research ethics board at a western Canadian university prior to data collection and any contact with nursing students. All third-year nursing students were invited to participate in this study. A written consent was obtained and used to inform each student of a number of considerations, including the purpose and procedures related to the study, the storage of data, confidentiality, and the right to withdraw. Students had the right to refuse to participate and refusal did not jeopardize student access to the course materials in any way. Students were reassured that their course standings would not be affected by participation in, or withdrawal from this study.

\section{Participants}

The nursing education program discussed in this article is a three-plus-one-year Bachelor of Science in Nursing (BSN) program in a large western Canadian university. In addition, this nursing program offers a Post-Degree Bachelor of Science in Nursing (PDBSN) degree for qualified students, which provides opportunity for full-time intensive study over six consecutive terms with program completion in less than two calendar years. The study participants $(\mathrm{n}=99)$ were a combination of PDBSN and BSN nursing students who were enrolled in concurrently required pediatric theory ( 24 hours) and pediatric clinical ( 78 hours) courses.

\section{Intervention}

The intervention was integrated in the pediatric theory and clinical courses, which are delivered in each of the three academic terms at the university. The intervention in the study involved an IPE component that included nursing students learning collaboratively within and across their discipline to support successful and effective collaboration with other health care professionals. In keeping with the IPE goals outlined by Health Canada, the IPE component of the intervention was designed based on the following objectives: 1) to socialize health care providers to work together in problem solving and decision-making; 2) to develop a mutual understanding of and respect for the contributions of other disciplines; and 3) to instill the competencies for collaborative practice (Canadian Interprofessional Health Collaborative, 2007). 
More specifically, the nursing students were taught the knowledge, skills, attitudes, and behaviours required to practice interprofessional collaborative (IPC) pediatric care. For example, the lecture focused on concepts of health promotion, wellness, self-determination, and individualized and safe care within an interprofessional and legally prudent environment. During the lecture, an interactive case study related to oral health was taught, highlighting the six competency domains essential for interprofessional collaborative practice, including: 1) interprofessional communication, 2) patient/client/family/community-centred care, 3) role clarification, 4) team functioning, 5) collaborative leadership, and 6) interprofessional conflict resolution (Canadian Interprofessional Health Collaborative, 2007).

Specifically, part one of the oral health intervention was delivered to all third-year students and included a combination of a two-hour didactic lecture coupled with an interactive case study approach from a public health dentist outlining the theoretical knowledge and assessment skills required to perform pediatric oral health care in practice. During the lecture, students were provided the opportunity to problem-solve case studies related to oral health, develop an understanding of oral health and respect for dentistry as a profession, and learn the competencies required for collaborative practice.

Part two of the intervention was administered by the nurse educator during the pediatric clinical course and included the addition of oral health content into the clinical skills lab, as well as learning related to comprehensive oral health assessment, primary prevention, and early care services. The purpose of adding these skills into the clinical lab was to reinforce the content taught within the theory course. Nursing and dental faculty members developed a detailed guide to oral health assessment, follow-up, and referrals to dental professionals (Spurr, Bally, \& Ogenchuk, 2015). The clinical lab intervention included education on the implementation of this tool into pediatric nursing practice, and provided the opportunity for students to ask questions and for faculty to provide feedback.

\section{Survey}

A suitable pre-tested questionnaire to identify student knowledge of oral health care of pediatric patients was not available. Therefore, a self-administered paper-based pre- and post-test survey which included 20 items on a three-point scale (Yes, No, and I don't know), was developed by faculty at the college of nursing and critiqued for content validity (Gall, Gall, \& Borg, 2003). The content of the questionnaire was developed based on oral health content from classroom lectures and the clinical practicum orientation. The questions were refined by a panel of oral health experts. Then, the revised questionnaire was pilot tested by administration to a group of 30 nursing students. The questions were evaluated in the pilot test based on a) comprehension of instructions, b) understanding of questions, and c) time to completion. Based on this feedback, a few items were revised with the intention of being transparent, relevant, and easy to understand. Moreover, based on the results of a survey administered to study participants in academic terms one and two, five additional items with the same three-point scale were added to both the pre- and post-test survey administered to students enrolled in the pediatric theory and clinical courses in term three.

\section{Data collection and analysis}

Data were collected over each of the three terms in which the courses were offered (September-August) in the 2013-2014 academic year. The pre-test was administered to all nursing students on the first day of the pediatric theory course and included items that evaluated 
student knowledge upon entering the pediatric course. The post-intervention survey was administered on the final day of the theory or clinical course.

Statistical Package for Social Sciences (SPSS 22.0) software was used to analyze the data collected. The three-point scale was recoded to facilitate analysis and resulted in the response "Yes" being given a score of 1 and the responses of "No" and "I don't know" given scores of 0. Thus, possible scores for each item ranged from $0.00(0 \%)$ to $1.00(100 \%)$. Because statistically significant differences were not found between terms, data for all three terms were grouped together for analyses. Paired-sample t-tests were conducted to compare pre- and postintervention scores for each individual item and for the overall questionnaire. Effect sizes (Cohen's d) were calculated as a practical measure of significance, where 0.2 is small, 0.5 is medium, and 0.8 is large.

\section{Results and discussion}

Participation rates for the surveys varied each term and are outlined in Table 1. Data from participants who did not complete both the pre- and post-intervention survey were excluded from the study. Overall, data for 99 students were used and are summarized along with relevant statistics in Table 2.

Table 1

\section{Participation Rates}

\begin{tabular}{lccc}
\hline & Term 1 & Term 2 & Term 3 \\
\hline Number of Responses $(\mathrm{n})$ & 15 & 17 & 67 \\
\hline Percent participation of total population & $39 \%$ & $52 \%$ & $53 \%$ \\
\hline
\end{tabular}

Table 2

Pre- and post-survey results

Items completed by students in Terms 1-3

\begin{tabular}{l|ll|ll|l}
\hline Item & Pre & & Post & Statistical information \\
& M & SD & M & SD & \\
\hline $\begin{array}{l}\text { 1. Early childhood caries is the } \\
\text { most common chronic childhood } \\
\text { disease recognized in Canada. }\end{array}$ & .35 & .48 & .94 & .24 & $\mathrm{t}(98)=-11.31, \mathrm{p}<.001, \mathrm{~d}=-1.55$ \\
\hline $\begin{array}{l}\text { 2. The health of the mouth impacts } \\
\text { the health of the body. }\end{array}$ & .99 & .10 & 1.00 & .00 & $\mathrm{t}(98)=-1.00, \mathrm{p}=.320, \mathrm{~d}=-.14$ \\
\hline $\begin{array}{l}\text { 3. Strep. } \text { mutans is the bacteria } \\
\text { that causes dental caries. }\end{array}$ & .13 & .34 & .37 & 54 & $\mathrm{t}(97)=-3.95, \mathrm{p}<.001, \mathrm{~d}=-.53$ \\
\hline $\begin{array}{l}\text { 4. The mother can transmit } \\
\text { bacteria to the child that } \\
\begin{array}{l}\text { contributes to the development of } \\
\text { dental caries. }\end{array}\end{array}$ & .53 & .50 & .89 & 32 & $\mathrm{t}(98)=-6.91, \mathrm{p}<.001, \mathrm{~d}=-.86$ \\
\hline $\begin{array}{l}\text { 5. It is recommended that children } \\
\text { should first see a health }\end{array}$ & .63 & .49 & .90 & .30 & $\mathrm{t}(98)=-5.31, \mathrm{p}<.001, \mathrm{~d}=-.66$ \\
\hline
\end{tabular}




\begin{tabular}{|c|c|c|c|}
\hline $\begin{array}{l}\text { professional for dental care by the } \\
\text { age of } 12 \text { months. }\end{array}$ & & & \\
\hline $\begin{array}{l}\text { 6. Risk factors for early childhood } \\
\text { caries are multifactorial. }\end{array}$ & $.96 \quad .20$ & 1.00 .00 & $t(98)=-2.03, p=.045, d=-.28$ \\
\hline $\begin{array}{l}\text { 7. Early childhood caries can cause } \\
\text { developmental delay in speech, } \\
\text { physical growth, and psychological } \\
\text { trauma. }\end{array}$ & $.60 \quad .49$ & $.96 \quad .20$ & $\mathrm{t}(98)=-6.91, \mathrm{p}<.001, \mathrm{~d}=-.96$ \\
\hline $\begin{array}{l}\text { 8. Bleeding gums is a sign of oral } \\
\text { disease. }\end{array}$ & $.63 \quad .49$ & $.67 \quad .47$ & $\mathrm{t}(98)=-.94, p=.348, d=-.08$ \\
\hline $\begin{array}{l}\text { 9. Dental caries initially appear as } \\
\text { white spots on the surface of the } \\
\text { tooth, usually near the gum } \\
\text { margin. }\end{array}$ & $.20 \quad .40$ & $.55 \quad .50$ & $t(98)=-5.61, p<.001, d=-.77$ \\
\hline $\begin{array}{l}\text { 10. The ingestion of medication } \\
\text { can contribute to cavities. }\end{array}$ & $.63 \quad .49$ & $.80 \quad .40$ & $t(98)=-3.60, p=.001, d=-.38$ \\
\hline $\begin{array}{l}\text { 11. Fluoride is most cost-effective } \\
\text { method to prevent cavities at a } \\
\text { population health level. }\end{array}$ & $.64 \quad .48$ & $.97 \quad .17$ & $t(98)=-6.70, p<.001, d=-.92$ \\
\hline $\begin{array}{l}\text { 12. Plaque is a sticky layer of germs } \\
\text { in our mouth. }\end{array}$ & $.80 \quad .40$ & $.91 \quad .29$ & $t(98)=-2.46, p=.016, d=-.31$ \\
\hline $\begin{array}{l}\text { 13. Children and adults alike should } \\
\text { brush their teeth for } 2 \text { minutes } \\
\text { total. }\end{array}$ & $.76 \quad .43$ & $.86 \quad .35$ & $t(97)=-1.99, p=.049, d=-.26$ \\
\hline $\begin{array}{l}\text { 14. Primary teeth are important to } \\
\text { support and guide the growth of } \\
\text { the permanent teeth. }\end{array}$ & $.82 \quad .39$ & $.98 \quad .14$ & $t(98)=-4.35, p<.001, d=-.55$ \\
\hline $\begin{array}{l}\text { 15. Children should brush their } \\
\text { own teeth at the age of } 3 \text { with the } \\
\text { supervision of their parents. }\end{array}$ & $.74 \quad .44$ & $.77 \quad .42$ & $t(98)=-.60, p=.551, d=-.07$ \\
\hline $\begin{array}{l}\text { 16. Children with dental caries } \\
\text { should see a dentist. }\end{array}$ & $.98 \quad .14$ & $.99 \quad .10$ & $t(98)=-.58, p=.566, d=-.06$ \\
\hline $\begin{array}{l}\text { 17. A child that has dental caries } \\
\text { with an infection present may also } \\
\text { have an abscess. }\end{array}$ & $.73 \quad .57$ & $.97 \quad .17$ & $t(98)=-4.35, p<.001, d=-.57$ \\
\hline $\begin{array}{l}\text { 18. Children who are in the } \\
\text { presence of cigarette smoke or } \\
\text { who smoke themselves are at } \\
\text { greater risk of developing dental } \\
\text { caries. }\end{array}$ & $.70 \quad .46$ & $.87 \quad .34$ & $t(81)=-4.12, p<.001, d=-.42$ \\
\hline $\begin{array}{l}\text { 19. A child is more likely to have } \\
\text { decay if their parents have dental } \\
\text { caries. }\end{array}$ & $.71 \quad .46$ & $.90 \quad .30$ & $t(81)=-3.87, p<.001, d=-.49$ \\
\hline
\end{tabular}




\begin{tabular}{l|ll|ll|l}
\hline $\begin{array}{l}\text { 20. Socioeconomic status is } \\
\text { considered a risk factor for the } \\
\text { development for oral caries. }\end{array}$ & .96 & .19 & .99 & .11 & $t(81)=-1.00, p=.320, d=-.19$ \\
\hline
\end{tabular}

\begin{tabular}{|c|c|c|c|}
\hline Item & $\begin{array}{ll}\text { Pre } & \\
\text { M SD }\end{array}$ & $\begin{array}{l}\text { Post } \\
M \quad S D\end{array}$ & Statistical information \\
\hline $\begin{array}{l}\text { 21. Periodontal disease increases } \\
\text { future risk for cardiovascular } \\
\text { disease. }\end{array}$ & $.52 \quad .50$ & $.93 \quad .26$ & $t(66)=-6.68, p<.001, d=-1.03$ \\
\hline $\begin{array}{l}\text { 22. Oral piercing can lead to } \\
\text { increased risk for oral infections } \\
\text { and trauma to the mouth. }\end{array}$ & $.91 \quad .29$ & $.99 \quad .12$ & $t(66)=-2.31, p=.024, d=-.36$ \\
\hline $\begin{array}{l}\text { 23. Alcohol use can lead to oral } \\
\text { health complications such as soft } \\
\text { tissue abnormalities, gingival } \\
\text { inflammation, and significant levels } \\
\text { of dental caries. }\end{array}$ & $.83 \quad .38$ & $.89 \quad .31$ & $t(65)=-1.07, p=.288, d=-.17$ \\
\hline $\begin{array}{l}\text { 24. Oral health assessment can } \\
\text { lead to early detection of diabetes } \\
\text { in children. }\end{array}$ & $.55 \quad .50$ & $.82 \quad .39$ & $t(66)=-3.88, p<.001, d=-.60$ \\
\hline $\begin{array}{l}\text { 25. Children diagnosed with } \\
\text { diabetes are at higher risk for } \\
\text { dental caries. }\end{array}$ & $.52 \quad .50$ & .79 .51 & $t(66)=-3.56, p=.001, d=-.53$ \\
\hline Total & $.67 \quad .15$ & $.86 \quad .10$ & $t(98)=-15.06, p<.001, d=-1.49$ \\
\hline
\end{tabular}

Nursing students' knowledge significantly improved following the intervention, as illustrated by a mean score of $67 \%$ on the pre-test and $86 \%$ on the post-test. This increase in knowledge was statistically significant with a large effect size $(\mathrm{t}(98)=-15.06, \mathrm{p}<.001, \mathrm{~d}=-1.49)$. In total, correct responses in the post-intervention survey increased significantly on 19 items with effect sizes ranging from small to large.

Our investigation of nursing student knowledge before and after a two-part oral health education intervention provides evidence of learning and statistical support for the need to incorporate oral health knowledge into nursing education. There were five items with large effects sizes that suggested the students learned significantly from pre-test to post-test. The highest score and greatest learning occurred with item \#1, which evaluated the students' knowledge about the prevalence of chronic oral disease in childhood. On the pre-test, few students were aware that oral disease was a significant burden for many children across nations. Creating awareness of the severity and prevalence of oral disease is the first step to improving the overall oral health of children and youth worldwide.

The second highest score illustrating that significant learning occurred was from item \#21, which evaluated the students' knowledge that periodontal disease increases future risk for cardiovascular disease (CVD). A meta-analysis suggested that periodontal disease is associated 
with increased risk of development of CVD by approximately $19 \%$ in the general population (Janket, Baird, Chuang, \& Jones, 2003; Lockhart et al., 2012). However, these authors identify that further research is needed to confirm this link in younger populations. Regardless, in the present study, the nursing students gained an understanding about the potentially significant risk associated with periodontal disease and about how promoting excellent oral hygiene beginning at a young age is an important component of leading a healthy life generally (Canadian Dental Association, 2012c).

The third and fourth highest scores measured equal improvements in learning and included items \#4 and \#7. These items evaluated nursing students' knowledge related to maternal transmission of bacteria to the child that contributes to the development of dental caries and the impact that early childhood caries (in its severest forms) can have on developmental delay in speech, physical growth, and psychological trauma. It is now understood that treating an expectant mother's oral health may decrease the transmission of streptococci bacteria to their children, and expectant mothers are now being actively engaged in targeted oral health programming (Saskatchewan Prevention Institute, 2014). Transmission commonly occurs via everyday activities (i.e., sharing feeding utensils, cleaning a pacifier with parent's mouth) (Saskatchewan Prevention Institute, 2014). Pregnancy often represents a unique learning opportunity where knowledge can have an impact on both maternal and early childhood oral health. The inclusion of oral or dental screenings by health professions (e.g., nurses) reflects the importance of oral health to overall health (U.S. Department of Health and Human Services, 2003). In addition, studies have found that oral health can affect a person's quality of life. Oral pain, missing teeth, and oral infections can influence a child's ability to speak, eat, and socialize; thus, influencing the child's to growth and development (Canadian Dental Association, 2012c).

The fifth highest score in which significant learning occurred was item \#11 which evaluated the students' understanding that fluoride is the most cost-effective method to prevent cavities at a population health level. The prevention of oral caries through fluoride varnish and supplementation are concepts that are beginning to emerge in some health care professional programs (Douglass, Douglass, \& Silk, 2005; Golinveaux et al., 2013). Fluoride varnish is widely known to be safe as well as the most cost-effective method to prevent cavities at a population health level (Golinveaux et al., 2013; Jablonski et al., 2014). The WHO identified the effective use of fluoride as a priority action area for the improvement of oral health worldwide (Petersen, 2009). These five items measured significant learning and provide new evidence to support the need to include this knowledge into nursing education programs.

The remaining 14 significant items had small-medium effect sizes. For example, few students recognized that children's primary teeth are important, that parents should brush these teeth for two minutes, and that the child should see a dentist health professional in the first year of life. These findings are consistent with other studies conducted with medical residents and nurse practitioners, and they reflect a lack of student knowledge in the area (Golinveaux et al., 2013; Minah et al., 2008; Wawrzyniak et al., 2006). The present study adds to the literature by confirming this trend with undergraduate nursing students, and it illustrates the need to further educate health professionals about the importance of pediatric oral health.

Additional new findings include the discovery that students have a poor understanding of the pathophysiology and general implications of oral health. Study results illustrate that significant learning occurred on several oral health concepts, including knowledge that Streptococcus mutans bacteria cause decay. Although participants had some understanding of 
oral health, significant gaps clearly remained. Similar to research conducted by Hallas and Shelley (2009) in the United States, we argue that enhancement of nursing education curricula is needed to support the expansion of comprehensive oral health care into pediatric nursing practice.

Other important findings include improved student knowledge related to the risks for oral disease in children and adolescents. For example, prior to the intervention, our participants had a limited understanding of many items related to oral health risks in children, including 1) multifactorial risk factors for childhood caries; 2) ingestion of medication contributing to cavities; 3) oral piercing increasing the risk for oral infections and trauma to the mouth; 4) the greater risk of developing dental caries in children who are in the presence of cigarette smoke or who smoke themselves; and 5) the greater likelihood of a child having decay if their parents have dental caries. Because oral health can be a reliable and indicator of general health, these risk factors are important to consider in pediatric nursing care (Percy, 2008). However, compared to other health issues in children and adolescents, oral health does not seem to receive attention in nursing practice (Blevins, 2011; Hallas \& Shelley, 2009; Johnstone et al., 2010; Marrs, Trumbley, \& Malik, 2011). As such, it was not surprising that many students were also not aware that that children diagnosed with diabetes are at higher risk for dental caries (Gillis, 2010). As outlined previously, this lack of knowledge is likely due to the lack of integration of oral health pedagogy into the nursing curricula (Golinveaux et al., 2013; Jablonski et al., 2014). We believe that inclusion of such content can result in students who are knowledgeable and competent in risk assessment and management, who can support nurses in feeling comfortable with oral health promotion, and who are capable of promoting oral health.

Despite assessment courses offered in this nursing education program, this study found that nursing students lacked information related to oral health assessment. Few nursing students understood that dental caries appear as white spots on the teeth, that plaque is a sticky layer of germs, that oral infection may present with an abscess, or that proper assessment can lead to the detection of disease such as diabetes. These are basic assessment skills that can lead to early detection and prevention of oral disease, yet nursing students appear to be inadequately prepared with the important components of a pediatric oral health assessment. Similar to Jablonski et al. (2014), we argue that it is imperative for nurses to be aware that the mouth is an early warning system, and routine inspection and assessment of the mouth can assist in identifying early symptoms of serious illness such as cancer or cardiovascular disease.

It is important to note that six items were not significant in this study: \#2- The health of the mouth impacts the health of the body; \#8-Bleeding gums is a sign of oral disease; \#15Children should brush their own teeth at the age of three with the supervision of their parents; \#16- Children with dental caries should see a dentist; \#20- Socioeconomic status is considered a risk factor for the development oral caries; \#23-Alcohol use can lead to oral health complications such as soft tissue abnormalities, gingival inflammation, and significant levels of dental caries. Perhaps the nursing students learned this oral health information in previous courses or these concepts may be common knowledge. However, it remains relevant and essential information, and, therefore, nurse educators should consider integrating this knowledge into their curricula to reinforce this information so that nurses are knowledgeable and comfortable with promoting oral health in children and adolescents. 


\section{Limitations}

The research was conducted using a modest sample from one large western Canadian university. However, the participants were from the largest non-departmentalized college at the university, which is also a distributed college and operates as one academic unit from three main locations in the province. In addition to the primary sites, undergraduate nursing education is also available to students from several distributed sites across the province. As such, these findings are reflective of nursing education in the province and appear congruent with global findings. Further investigation with a larger sample is needed to validate these results.

Another limitation is the lack of control group for the intervention. Due to ethical implications, all nursing students were given the educational oral health intervention. A final limitation was the response format where all correct answers were "yes." Although the percentage of correct responses varied widely by item, it is possible that some students realized that the correct response was the same for all items, which contributed to an inflated knowledge score. Subsequent research designs including a control group and items with a correct response of "no" or using a multiple choice response format should be considered to validate these results.

\section{Implications for nursing education}

The findings reported herein illustrate that oral health education can enhance nursing student knowledge and understanding of pediatric oral health care. The highest scores that provided evidence of learning included items assessing knowledge related to the prevalence of oral disease, the risks of periodontal disease, that the mother can transmit bacteria to the child that contributes to the development of dental caries, early childhood caries can influence a child's growth and development, and the importance of fluoride varnish and supplementation. Other significant findings with small-medium effect sizes that indicated learning had occurred after the two-part intervention included 1) the importance of oral health care, 2) the pathophysiology and implications of oral health, 3) the risk factors of oral health, and 4) assessment. Similar results have been found in nurse practitioner and medical students. However, these findings provide in-depth information on the oral health knowledge in nursing students. In addition, this study is the first confirmation of this trend in undergraduate nursing students and illustrates the continued need for inclusion of oral health knowledge into nursing education programs globally (Golinveaux et al., 2013; Jablonski et al., 2014). Similar to Hayes (2014), however, we argue that nurses play a key role in the promotion of oral health care, and a sustainable improvement in oral health outcomes will require all health care professionals to learn about and implement oral health care into pediatric practice.

Comprehensive pediatric oral health pedagogy is now included in the curricula for our undergraduate nursing students, and we have established a partnership with the college of dentistry and public health dental therapists to facilitate the IPE oral health pedagogy. As a result, our nursing students are empowered with the knowledge and skill to articulate a message of prevention and promote good oral health care to clients beginning at an early age. Nursing students have a real opportunity to affect positive change that will improve children's oral health. Another long-term benefit is that nursing students have a new understanding of their role in oral health and are more prepared to address oral health challenges faced by children. Finally, the oral health learning experiences provide nursing students with the knowledge and tools required to continue practicing oral health in future clinical practice. 
In addition to nursing education learning experiences, we recommend developing policies that are designed to optimize the potential for nurses to impact existing oral health disparities. To accomplish this task, nurses should consider soliciting leadership at a national level to develop policies that are supportive of oral health nursing curriculum and practice guidelines (Hallas \& Shelley, 2009). In our local nursing education program, nursing students are educated with respect to the importance of policies that support the practice of oral health care, leading to longterm sustainability in addressing these issues through the emerging interprofessional workforce. Nursing students provide a consistent approach to screening and offering health care to high-risk pediatric clients. They do so using appropriate policies and procedures related to interprofessional referral pathways established and learned through their nursing education.

\section{Conclusion}

Oral health education can enhance nursing student knowledge and understandings of pediatric oral health challenges and related health care. The new and unique findings from this study present evidence to support an approach to nursing education that gives high priority to the inclusion of oral health into nursing curricula. This knowledge and experience has been developed and is consistently incorporated into the local nursing curricula so that students can advocate for children and families, and provide individualized, safe, and quality oral health care. Given the prevalence of oral disease in children and the importance of preventing this chronic disease, nurse educators worldwide should consider collaborating across disciplines to develop responsive oral health curricula. The related interprofessional teaching and learning will prepare nursing students with the foundation necessary to address the disparate oral health challenges experienced by children. 


\section{References}

Blevins, J. Y. (2011). Oral health care for hospitalized children. Pediatric Nursing, 37(5), 229235, quiz 236. Retrieved from http://www.ncbi.nlm.nih.gov/pubmed/22132567

Callister, L. M. (2008). Global oral health in women and children. Global Health and Nursing, $33(1), 60$.

Canadian Dental Association. (2010). Access to oral health care for Canadians. Retrieved from http://www.cda-adc.ca/en/about/position_statements/accesstocare/

Canadian Dental Association. (2012). CDA's definition of oral health. Retrieved from http://www.cda-adc.ca/en/about/position_statements/

Canadian Dental Association. (2012c). Oral health - Good for Life. Retrieved from http://www.cda-adc.ca/en/oral_health/cfyt/good_for_life/

Canadian Interprofessional Health Collaborative. (2007). Interprofessional Education and Core Competencies. Vancouver, BC: Author. Retrieved from http://www.cihc.ca/files/publications/CIHC_IPE-LitReview_May07.pdf

Caspary, G., Krol, D. M., Boulter, S., Keels, M. A., \& Romano-Clarke, G. (2008). Perceptions of oral health training and attitudes toward performing oral health screenings among graduating pediatric residents. Pediatrics, 122(2), e465-471. doi:10.1542/peds.20073160

Centre For the Advancement of Interprofessional Education. (2002). Defining IPE. Retrieved from http://www.caipe.org.uk/resources/defining-ipe/

Douglass, J. M., Douglass, A. B., \& Silk, H. J. (2005). Infant oral health education for pediatric and family practice residents. Pediatric Dentistry, 27(4), 284-291.

Federal Provincial and Territorial Dental Working Group. (2012). Canadian Oral Health Framework: 2013-2018. Retrieved from http://www.caphd.ca/sites/default/files/FrameworkOctober\%202014\%20\%20FINAL\%20English.pdf

Gall, M., Gall, L., \& Borg, W. (2003). Educational research: An introduction (7th ed.). Boston, MA: Pearson Education.

Gillis, M. R. (2010). A place for oral health in diabetes management. Journal of the Canadian Dental Association, 76(a24).

Golinveaux, J., Gerbert, B., Cheng, J., Duderstadt, K., Alkon, A., Mullen, S., ... Zhan, L. (2013). Oral health education for pediatric nurse practitioner students. Journal of Dental Education, 77(5), 581-590.

Hallas, D., \& Shelley, D. (2009). Role of Pediatric Nurse Practitioners in Oral Health Care. Academic Pediatrics, 9, 462-466. doi:https://doi.org/10.1016/j.acap.2009.09.009

Hayes, A. (2014). Filling a gaping hole in care. Canadian Nurse, 110(3), 44. 
Interprofessional Education Consortium. (2002). Creating, Implementing, and Sustaining Interprofessional Education. Retrieved from https://www.uth.edu/dotAsset/e75073f59d09-46e0-bb00-f4a54a2b1e6a.pdf

Jablonski, R., Mertz, E., Featherstone, J., \& Fulmer, T. (2014). Maintaining oral health across the lifespan. The Nurse Practitioner, 39(6), 39-46.

Janket, S. J., Baird, A. E., Chuang, S. K., \& Jones, J. A. (2003). Meta-analysis of periodontal disease and risk of coronary heart disease and stroke. Oral Surgery Oral Medical Oral Pathology Oral Radiology Endodology, 95(5), 559-569.

Johnstone, L., Spence, D., \& Koziol-McLain, J. (2010). Oral Hygiene Care in the Pediatric Intensive Care Unit: Practice Recommendations. Pediatric Nursing, 36(2), 85-96.

Kearney, K. J. (2008). Facilitating interprofessional education and practice. Canadian Nurse, 104(3), 22-26.

Kullberg, E., Sjogren, P., Forsell, M., Hoogstraate, J., Herbst, B., \& Johansson, O. (2010). Dental hygiene education for nursing staff in a nursing home for older people. Journal of Advanced Nursing, 66(6), 1273-1279. doi:10.1111/j.1365-2648.2010.05298.x

Lapkin, S., Levett-Jones, T., \& Gilligan, C. (2011). A systematic review of the effectiveness of interprofessional education in health professional programs. Nurse Education Today. doi:10.1016/j.nedt.2011.11.006

Lockhart, P. B., Bolger, A., Papapanou, P. N., Olusegun Osinbowale, O., Trevisan, M., Levison, M. E., ... Baddour, L. M. (2012). Periodontal Disease and Atherosclerotic Vascular Disease: Does the Evidence Support an Independent Association? Circulation, May, 125. doi:https://doi.org/10.1161/cir.0b013e31825719f3

Marrs, J. A., Trumbley, S., \& Malik, G. (2011). Early childhood caries: determining the risk factors and assessing the prevention strategies for nursing intervention. Pediatric Nursing, 37(1), 9-15, quiz 16.

Minah, G., Lin, C., Coors, S., Rambob, I., Tinanoff, N., \& Grossman, L. K. (2008). Evaluation of an early childhood caries prevention program at an urban pediatric clinic. Pediatric Dentistry, 30(6), 499-504.

National Children's Oral Health Foundation. (2012). America's toothfairy: Because every child deserves a healthy smile. Retrieved from http://www.ncohf.org

Percy, M. S. (2008). Oral health of adolescents-it's more than dental caries. MCN American Jourrnal of Maternal Child Nursing, 33(1), 26-31. doi:10.1097/01.NMC.0000305654.78871.ee

Petersen, P. E. (2009). Global policy for improvement of oral health in the 21 st centuryimplications to oral health research of World Health Assembly 2007, World Health Organization. Community Dentistry and Oral Epidemiology, 37, 1-8. doi:https://doi.org/10.1111/j.1600-0528.2008.00448.x

Saskatchewan Prevention Institute. (2014). Improving the Oral Health of Pregnant Women and Young Children. Retrieved from http://www.skprevention.ca/oral-health/ 
Satcher, D. (2009). Children's Oral Health: The Time for Change is Now. Academic Pediatrics, 9(6), 380-382. doi:https://doi.org/10.1016/j.acap.2009.09.020

U.S. Department of Health and Human Services. (2003). A National Call to Action to Promote Oral Health. Retrieved from https://www.nidcr.nih.gov/DataStatistics/SurgeonGeneral/NationalCalltoAction/Docume nts/NationalCallToAction.pdf

Wawrzyniak, M. N., Boulter, S., Giotopoulos, C., \& Zivitski, J. (2006). Incorporating caries prevention into the well-child visit in a family medicine residency. Family Medicine, $38(2), 90-92$. 